\title{
FRONTERA, MOVILIDAD Y CIRCULACIÓN RECIENTE DE PERUANOS Y BOlivianos EN EL NORTE DE Chile
}

\author{
Marcela Tapia Ladino ${ }^{1}$
}

\section{* InTROducCión}

Resumen

Desde los años 9o, Chile se ha convertido en uno de los destinos de la migración sudamericana a nivel continental. Sin embargo, a nivel local la región de Tarapacá ha contado con una alta presencia de fronterizos a lo largo de su historia. En este contexto, el estudio del espacio fronterizo es central para poner a prueba las nociones utilizadas en las investigaciones sobre migración que hemos utilizado hasta hace poco, entre ellos sociedad, frontera y migrantes. El análisis de las fuentes muestra que los patrones y tendencias migratorias en la región estudiada se ajustan mejor a conceptos más amplios e inclusivos como son los de movilidad y circulación. Ello porque al analizar la imbricación del marco jurídico, el mercado de trabajo fronterizo y las brechas de desarrollo del espacio colindante con Tarapacá producen un espacio de circulación, donde el retorno y el establecimiento multilocal — binacional - son sus rasgos característicos.

Palabras claves: frontera - movilidad - circulación - espacio fronterizo.

\begin{abstract}
Since the 1990 s, Chile has become a destination for South American migration at the continental level. However, at the local level, the Tarapacá region has had a high presence of border dynamics throughout its history.

In this context, the study of border space is central to testing notions that we have used in research on migration, including society, border and migrants. Our analysis of the literature shows that the migratory patterns and trends in the region under study are more reflective of broader and more inclusive concepts such as mobility and movement. This is due to the fact that the interweaving of the legal framework, the border labor market, and development gaps between the adjacent space of Tarapacá produce circulation space, where the return and multi-local (binational) establishment are its characteristic features.
\end{abstract}

Abstract

Key words: border - mobility - circulation - border area.

Recibido: Mayo 2014. Aceptado: Marzo 2015
Las regiones de frontera son espacios que en el último tiempo se han visto tensionados porque son, en muchos casos, las zonas de salida y entrada para los migrantes de dos o más países, y porque en reiteradas ocasiones son lugares desde donde se busca cruzar y pasar al otro lado a como dé lugar. En los últimos años, debido a las restricciones de ingreso a países del norte y la crisis reciente en Europa y Estados Unidos, se registra un aumento de las migraciones sur-sur e intrarregionales en América Latina lo que ha motivado la preocupación de las agencias internacionales (OIM 2013a, 2013c). Así, las regiones que colindan las fronteras son lugares de circulación de personas, tanto de aquellas que buscan cruzar para instalarse al otro lado o para seguir hacia otro destino, como para ir y venir aprovechando las oportunidades que encuentran por el hecho de cruzarla. Por tanto, estas regiones son espacios en los que se ponen a prueba dos nociones que se vinculan, frontera y migración, y que nos retan a discutir la forma y el tratamiento que se ha dado al examen de los movimientos de población fronteriza.

El concepto de migración utilizado tradicionalmente por los estudios migratorios no da suficientemente cuenta de los distintos tipos de movimientos que las personas realizan a lo largo de sus vidas, y los territorios que describen en los espacios por donde se mueven. Existe una producción sobre migración circular y temporal desarrollada en especialmente en México, asociada normalmente al establecimiento de trabajadores mexicanos por períodos variables en Estados Unidos, sin embargo se discute menos alcance de la noción de migración (Bustamante 1997; Canales 1999). En la actualidad se ha incluido la

1 Instituto de Estudios Internacionales INTE, Universidad Arturo Prat. Av. Arturo Prat 2120, Iquique, CHILE. Email: marcela.tapia@unap.cl 
noción de retorno para aludir a los regresos frecuentes como parte de una estrategia de movilidad de quienes migran (Durand 2006). La reciente crisis en Europa ha puesto en evidencia los movimientos de retorno de los migrantes y de circulación de personas que alternan oportunidades laborales, con las necesidades de los ciclos de vida familiar como parte del mismo proyecto migratorio (Marcu 2013). No se trata de fenómenos nuevos, sino de la necesidad de relativizar un concepto que no explica del todo las distintas formas de moverse en el espacio, y de la inadecuación de las herramientas conceptuales y metodológicas para captar esa "ambigüedad migratoria" (Cortés 2009: 38). Asimismo, la evidencia empírica invita a dejar de concebir las migraciones como rupturas espaciotemporales, para mirar las conexiones y vínculos que establecen quienes migran o se mueven, y así atender a la circulación de personas como una forma de movilidad (Heyman 2012; Mallimaci 2012).

El presente trabajo quiere aportar a una discusión más amplia sobre la movilidad y la migración e indagar por los patrones y tendencias migratorias de tipo fronterizo, peruano y boliviano que se han desarrollado en la región de Tarapacá en el contexto de su historia reciente de los años 9o, del siglo pasado hasta hoy. La metodología de investigación utilizada fue mixta, cuantitativa y cualitativa (qualititive driven) (Mason 2006), con el uso de métodos combinados guiados por preguntas de investigación que, partiendo un enfoque cualitativo reconoce la necesidad de cuantificar el fenómeno, caracterizarlo y tipificarlo para luego analizar el contexto histórico en que han ocurrido y los factores que explican el modelamiento de los patrones y tendencias de movilidad humana en la región de Tarapacá.

La investigación incluyó la revisión de fuentes primarias y secundarias. Respecto de las primeras, se consideró la realización de entrevistas a inmigrantes e informantes claves en las ciudades de Arica e Iquique en organizaciones como el Servicio Jesuita Migrante, la Organización de Bolivianos Residentes y la Casa de Acogida a Inmigrantes de la población Juan Noé de Arica y la Pastoral Migratoria, la Policía de Investigaciones y la coordinación del Programa de Refugio que dependen del Obispado de Iquique. Las entrevistas se hicieron en base a un cuestionario semiestructurado que se aplicó a fines del año 2012 y principios de 2013 en ambas ciudades a informantes claves e inmigrantes. En total se realizaron 19 entrevistas a inmigrantes peruano/as y boliviano/as con visa de turismo, sujeta a contrato y residentes, y 14 entrevistas a informantes claves de distintas organizaciones e instituciones de Arica e Iquique. La explotación de fuentes secundarias consideró la revisión de tesis en universidades locales, informes de trabajo y bibliografía especializada sobre migraciones y frontera. Asimismo, se consideró la explotación de material estadístico obtenida de la Policía de Investigaciones de Chile (PDI) sobre ingresos y salidas de extranjeros por las distintas avanzadas o pasos fronterizos del país.

El artículo se organiza de la siguiente forma: en la primera parte se realiza una revisión sucinta sobre la noción de frontera y los estudios que al respecto se han hecho en América Latina y Europa. Luego se incluye el marco teórico utilizado que considera el transnacionalismo y el paradigma de la movilidad para el estudio de los movimientos de población en espacios fronterizos. El tercer apartado corresponde a una descripción de la región fronteriza en estudio, sus rasgos geográficos y el análisis de los datos de la Policía de Investigaciones de Chile. La cuarta parte corresponde a los patrones de movilidad encontrados en el extremo norte del país sus características y rasgos a partir de los aportes de las entrevistas, para terminar con las conclusiones al final del trabajo.

\section{Las fronteras para el estudio de las migraciones y la movilidad}

Abordar el estudio de las regiones fronterizas implica casi siempre un desafío puesto que se trata de espacios de reciente configuración en la historia de América Latina, trazados en zonas de baja densidad, alejadas de los centros políticos y definidas como áreas aisladas y remotas (Amilhat-Szary y Rouvière 2009). De hecho, la definición de los contornos de los estados nacionales latinoamericano se inició con los procesos de independencia (1810), sin embargo no se terminaron de precisar sino hasta las primeras décadas del siglo XX, luego de una serie de conflictos y disputas (Amilhat-Szary 2013). Por tanto, las actuales fronteras son lugares que con frecuencia se encuentran afectados por demandas sobre el territorio, y son el recordatorio constante de las disputas decimonónicas, como ocurre en el caso estudiado (González 2004, 2008). 
En América Latina, la frontera más estudiada es la de México y Estados Unidos, donde existe una larga tradición sobre estudios fronterizos y sus distintas dimensiones, lo que le ha valido la connotación de paradigma (Vila 2001; Garduño 2002; Cueva 2005; Medina 2006). Como señala Zúñiga (2009), en los años 70 Miguel León-Portilla aportó la idea "sociedad norteña" como una variedad de la cultura mexicana y una singularidad característica, donde la vecindad era solo un dato para resaltar dicho rasgo. Más tarde en los años 80 , los estudios transitaron hacia la noción de "frontera invadida" para denunciar la influencia norteamericana, la pérdida de rasgos mexicanos - como por ejemplo, el idioma-, la discriminación y la presión de la cultura estadounidense. En síntesis, se vio a la frontera como un espacio de riesgo cultural. Luego, las investigaciones derivaron en estudios de corte nacionalista que reivindicaron lo "mexicano" como acto de afirmación frente a la penetración e influencia norteamericana. A fines de los 80 y principios de los 90 , las investigaciones sobre la frontera de México y Estados Unidos fueron vistas bajo el influjo de la posmodernidad, según la cual la frontera es "una zona con vocación cultural híbrida producida por entrecruzamientos culturales muy diversos y heterogéneos" (Zuñiga 2009: 74). Se plantea así la idea de sociedad fronteriza. El desarrollo más reciente va en la dirección de incluir la percepción que los propios mexicanos tienen de sí mismos y de la frontera (border perspective inside), y de la necesidad de considerar la interacción y la contigüidad como elementos centrales de la vida de la frontera (Solís 2009). Los trabajos más recientes reconocen la variedad de fronteras existentes en el linde entre México y Estados Unidos, dado por la diversidad regional y las economías regionales. Así advierte del riesgo que han supuesto los estudios centrados en Tijuana y San Diego y el estatus de arquetípica dado al linde, por tanto, de acuerdo a su magnitud y desarrollos regionales, no se trata una frontera unívoca (Zúñiga 2011).

En el último tiempo también se registra una preocupación por los estudios de frontera en Europa puesto que, luego de las distintas ampliaciones del espacio Schengen, se ha reforzado la frontera externa europea en un proceso de contradicción entre libre circulación por dentro y clausura hacia afuera (Ribas 2011; Zapata-Barrero y FerrerGallardo 2012a). Asimismo, la crisis humana que cada verano genera el naufragio de las pateras o los intentos desesperados de cruzar las vallas de Ceuta y Melilla, han motivado una preocupación por los centros de atención y detención de migrantes, los campamentos (Campero) como "no espacios" debido al constante estado de excepción que viven allí los subsaharianos. Del mismo modo crece la preocupación por la presión que la Unión Europea impone a España para evitar el ingreso de más "ilegales" entre Marruecos y la Unión, y el tránsito del refugio y el asilo a las políticas de securitización (Johnson 2013).

En el Cono sur de América Latina también ha crecido en interés por estudiar las fronteras por distintos motivos, entre ellos, por el aumento de la migración intrarregional (Sassone 2010; Benedetti y Salizzi 2011a; Benedetti y Salizzi 2011b; Texidó y Gurrieri 2012), por los procesos de securitización y tráfico de ilícitos (Bello 2012; Corder y Ruiz-Tagle 2013) y la necesidad de comprender los significados de las barreras geográficas como fronteras y el aislamiento histórico que han padecido los espacios fronterizos (Nuñez 2011; Nuñez et al. 2013). Todavía faltan puntos de confluencia entre las distintas disciplinas que tienen como centro a las fronteras, pero sin duda es una línea de investigación que crece rápidamente. De este modo, las regiones fronterizas adquieren cada vez mayor notoriedad porque son la puerta de personas que ingresan y salen de sus países y se constituyen en el filtro de quienes son permitidos.

La noción de frontera es ampliamente utilizada en las ciencias sociales con fines distintos y significados diversos, y en el último tiempo aparece frecuentemente citada en los estudios sobre globalización (Johnson et al. 2011; Zapata-Barrero y Ferrer-Gallardo 2012b). Paradójicamente, esta noción no tiene fronteras muy precisas, y en muchos casos se produce confusión sobre su significado. Por tanto, se trata de un debate amplio que ha transitado por distintos momentos, desde la preocupación por la línea en clave geopolítica (1950) hasta el interés por la interacción y el intercambio (Johnson et al. 2011). En la actualidad, los estudios sobre fronteras o border studies han experimentando un renacimiento especialmente después de la caída del Muro de Berlín (1989) y la proclamación del fin de las fronteras, para luego volver a la preocupación por las líneas divisorias tras los atentados del 22-S. Hoy se reconoce la necesidad de una teorización constante y situada sobre las fronteras más que una teoría general y única, de modo que la transdisciplinariedad es una 
práctica teórico metodológica que se propicia en estudios más recientes (Paasi 2011; Donzelli 2014).

Para este estudio se consideraron las interpretaciones que buscan comprender las fronteras como la suma de procesos sociales, económicos, culturales y políticos que centran la mirada desde los bordes (border inside perspective) más que como demarcadores o líneas fijas (Johnson et al. 2011). Aunque se reconoce la existencia de enfoques que privilegian los procesos en sentido inverso, es decir, de fronterización, restricción y clausura de las fronteras como ocurre con el borde exterior de la Unión Europea (Ribas 2011). Estas contradicciones entre cierre y apertura no las podemos comprender si no incluimos en el análisis la escala, es decir, tener en cuenta que las viejas jerarquías, como lo nacional, no han desaparecido del todo, sino que surgen nuevas escalas que vencen a las primeras y las reducen a un campo más exclusivo que en el pasado (Sassen 2007: 27).

Para mayor precisión, es central adherir a una definición de región fronteriza, que en este caso la entendemos como espacios de "desarrollo de un conjunto de actividades al interior de cada estado y que tienen a la frontera como un centro vital de referencia" (Morales 2010). La región incluye no solo la línea - el límite - sino el área de influencia de la frontera sobre un territorio. Se trata, por tanto, de zonas donde se sintetizan las acciones de convergencia de espacios contiguos - dos o más Estados-, pero que son también espacios de contradicción, es decir, que oscilan entre interacción y restricción, apertura y cierre. Al mismo tiempo, las regiones fronterizas son el recordatorio de las consecuencias sociales y políticas del proceso de definición y redefinición de los límites (Newby 2006). Por último, para este trabajo importó el sentido histórico, geográfico y territorial de las fronteras, y los patrones que describen a partir de los cruces y la circulación de personas de origen fronterizo.

\section{Enfoque transnacional y paradigma de la movili- dad para el estudio del espacio fronterizo}

En otro trabajo he señalado que el enfoque transnacional es un punto de partida adecuado para el estudio de la movilidad humana en zonas de frontera (Tapia y Ramos, 2013). Las razones se relacionan con que, desde sus orígenes, el transnacionalismo ha buscado discutir las limi- taciones del nacionalismo metodológico para atender a los vínculos y lazos que establecen las personas por sobre las fronteras y a las formas de vidas multilocalizadas que involucran a dos o más territorios (Faist 2000; Bryceson y Vuorela 2002; Glick Schiller 2008). Estos aportes han permitido superar los supuestos contenidos en los estudios migratorios clásicos como la visión dicotómica formada principalmente por dos espacios, origen y destino, y por el establecimiento como objetivo central de la migración.

En este sentido, el enfoque transnacional invita a mirar fenómenos que no son del todo nuevos, pero que adquieren visibilidad cada día; en este caso interesa el carácter transfronterizo en tanto atiende a la concatenación de vínculos y prácticas que unen a las personas que migran, así como las redes, flujos y los entramados que se tejen a partir de la movilidad. El enfoque transnacional converge así con la teoría de las redes, en tanto ayuda a comprender la sostenibilidad de los vínculos transfronterizos que crean un sentimiento de bienestar, especialmente visible en el caso de las familias transnacionales (Bryceson y Vuorela 2002) y la maternidad transnacional (Hochschild 2000), entre otros fenómenos. En el caso de la migración fronteriza vimos que la acción de las redes migratorias es importante en Tarapacá pero no necesaria, como ocurre en las migraciones internacionales (Bardají 2006; Tapia y Ramos 2013). La contigüidad y la cercanía permiten "saltar sin red" en muchos casos, o valerse de los dispositivos de acogida, como la Pastoral Migratoria, especialmente durante el primer tiempo o en los períodos sin trabajo a la llegada.

Los debates más recientes del transnacionalismo critican la importancia dada a la dimensión desterritorializada de los vínculos y entramados sociales (campo social transnacional o espacio social transnacional) (Faist 2000; Vertovec 2003; Levitt 2011) lo que ha llevado a hacer caso omiso del vínculo con el territorio, o al menos su desatención, olvidando por añadidura que la migración significa "conexiones transfronterizas" (Waldinger 2013). Así, "en lugar de constituir un mero flujo de personas, recursos e imágenes itinerantes y en circulación, el transnacionalismo está presente en los lugares concretos en los que los inmigrantes viven sus vidas y realizan sus prácticas itinerantes" (Sinatti 2008: 106); es decir, no hay que olvidar que la migración $-\mathrm{y}$ movilidad en general - existen en 
la medida que hay lugar o lugares a los que se pertenece y de los que se ha partido. "Las migraciones son, por naturaleza, procesos sociales informados por un sentido de lugar" (Sinatti 2008: 106).

Las revisiones más recientes del enfoque transnacional incorporan elementos que han renovado la mirada de la migración, especialmente a partir de la crisis europea y los movimientos de retorno que ésta ha suscitado ( $\mathrm{Si}$ natti 2010; Marcu 2013; Parella 2013). En general, las investigaciones e informes sobre migración utilizan la noción de migrante como aquéllos que se establecen por un período de tiempo en un lugar ${ }^{2}$. Esta noción alude al establecimiento en un territorio en clave nacional, y al retorno como el fin de esa permanencia, una vez conseguidos los objetivos del proyecto migratorio. Estas presunciones han dado por resultado un sentido dicotómico de los movimientos de población —origen y destino- y la desatención del retorno y la circulación como parte del movimiento de población, y no como su término. En general, los presupuestos contenidos en el concepto poseen una mirada estadocéntrica, dejando voluntaria o involuntariamente fuera una serie de otros tipos de movimientos que escapan a esta definición, y que en ocasiones han sido tratadas como categorías residuales (Heyman 2012; Mallimaci 2012) o ambiguas (Cortés 2009).

La geografía social francesa ha desarrollado lo que se denomina "antropología del movimiento", basada en el "paradigma de la movilidad" de Tarrius (2007), expresión que alude a aquellos movimientos de personas "móviles" que generan territorios. El autor llama la atención por aquellos movimientos de personas que, desde el punto de vista de las teorías migratorias, no tienen como fin el establecimiento, pero que sin embargo desde el paradigma de la movilidad generan e instauran territorios. Se trata de una propuesta epistemológica que se basa en una "concepción sobre la territorialidad entendida como objetivación materializada de los trayectos de los agentes sociales" (Mallimaci 2012: 80); es decir, que son producidas por las relaciones sociales de quienes la transitan (Mancano 2010). Según esta propuesta quedan obsoletas las diferenciaciones entre movilidades y migraciones,

2 Según el Informe 2011 del Fondo de Población Naciones Unidas, un migrante es una persona que se establece en un lugar distinto al de nacimiento por al menos un año (Crossette 2011). "las segundas realizan una dimensión de las primeras, exigiendo una atención particular a las diversas dimensiones de las relaciones entre espacios y tiempos señalados" (Payá 2007: 48). De este modo, Tarrius acuña la noción de circulación migratoria para referirse "al conjunto de flujos humanos materiales e inmateriales, que irrigan el campo migratorio y el espacio relacional multipolarizado de una población; sabiendo que esta población vive cada día una alteridad interactiva en su espacio de destino como en su espacio de origen, gracias a varios flujos de circulación" (Cortés 2009: 39). En síntesis, de acuerdo a estos aportes es posible atender a las dinámicas que producen y definen las circulaciones, a las modalidades que adquieren, a los actores "conexos" (no migrantes, pasadores, transportistas) y los "recursos circulatorios" es decir, al saber y poder circular de quienes se mueven (Cortés 2009: 40) y al sentido que dan a esas prácticas espaciales.

Estos aportes permiten alcanzar una visión más amplia de la migración y los movimientos de población, que son pertinentes para el estudio de los espacios de frontera y que constituyen el marco con el que abordamos el análisis posterior. En este sentido, la noción de movilidad “... es más útil porque es más amplia, abarca más y hace menos juicios acerca de la naturaleza del movimiento (duración, propósito, posición social) que la migración y otras conceptualizaciones estrechas" (2012: 427). Este concepto, en el marco del paradigma de la movilidad, permite analizar la variedad de movimientos que ocurren en una región fronteriza, entre las que se encuentran los movimientos diarios, semanales, quincenales y mensuales, así como la instalación de las personas en un lado de la frontera y la mantención de vínculos con el otro lado. Estos movimientos pueden estar en más o menos concordancia con el marco jurídico sobre extranjería y la acción del mercado laboral fronterizo en el que los sujetos se mueven de acuerdo a lógicas del mercado que requiere cada vez más mano de obra flexible y móvil.

\section{Movilidad y circulación en el espacio fronterizo ta- rapaqueño}

Normalmente, la caracterización de la región de estudio se ha realizado desde una perspectiva nacional. Esta vez la opción es caracterizar la región fronteriza desde una mirada más amplia que incluya al espacio circunvecino. 


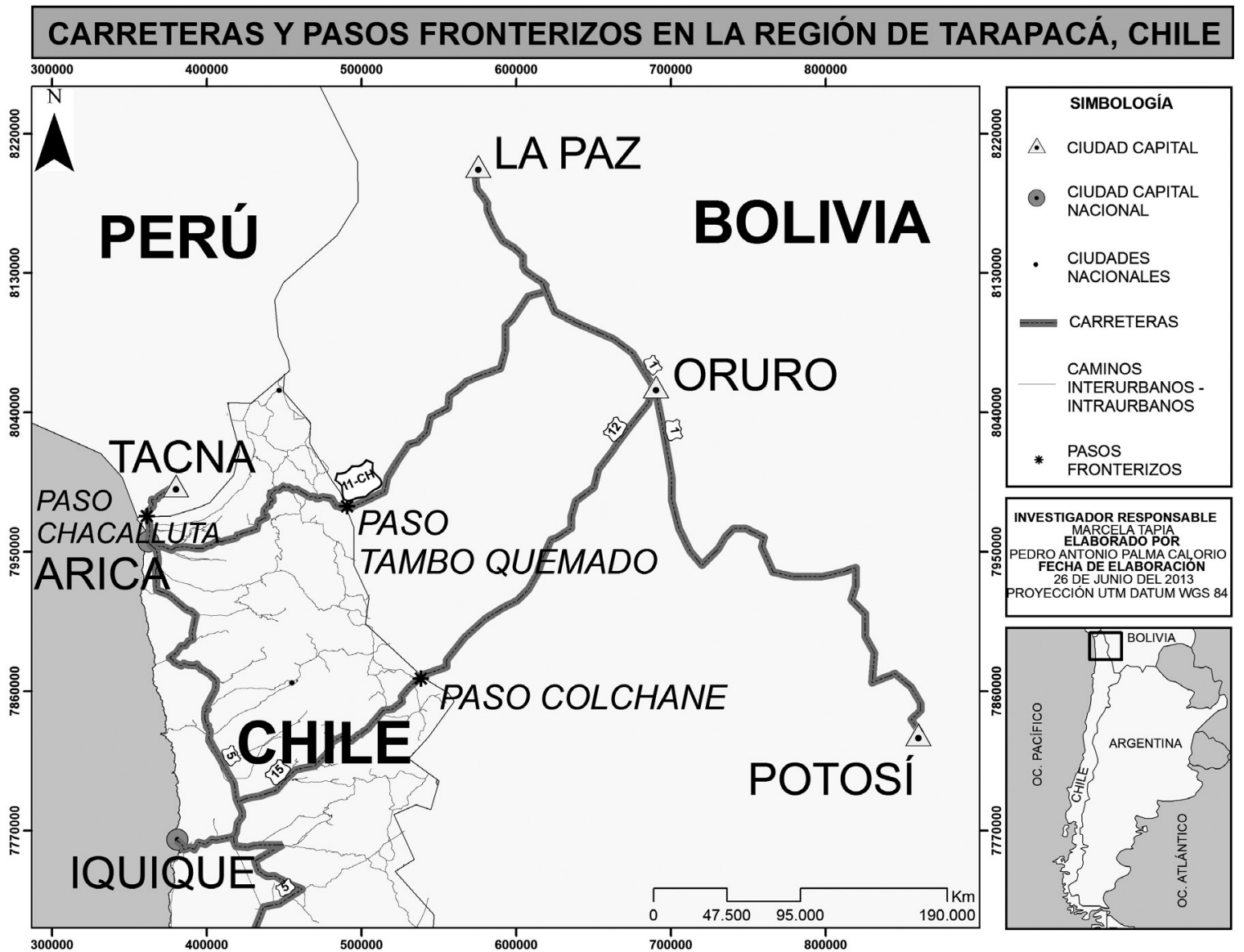

Figura 1. Arica-Parinacota (2007), Tarapacá y los departamentos fronterizos.

Tarapacá y los departamentos adyacentes poseen elementos comunes desde el punto de vista geográfico, histórico y demográfico que es preciso señalar. En primer término, la región de Tarapacá hasta antes de la creación de la XV región compartía 167,6km de frontera con Perú, que corresponde al departamento de Tacna. Este departamento, como la región chilena en estudio, se ubican alejados de los centros políticos de sus respectivos países en $1310 \mathrm{~km}$ de Lima, en el caso de Tacna, y más de 2000 $\mathrm{km}$ de Santiago, en el caso de Arica. Desde el punto de vista demográfico, el departamento de Tacna cuenta con una población de 324.498 habitantes según datos del INEI de 2011, lo que representa el 1,1\% de la población peruana total (INEI).

En el caso de la I Región de Tarapacá hasta el 2007, y luego con la creación de la XV Región de Arica y Parinacota, se estimó una población de ambas en casi 500 mil habitantes, según datos del INE de 2010. Sin embargo, la actual XV Región posee una población estimada de 185 mil habitantes (INE 2010) y es una de las regiones de menor crecimiento nacional, e incluso registra pérdida de población en los últimos censos. Este hecho ha llamado la atención de organismos de seguridad ${ }^{3}$ y explica el déficit de mano de obra en la zona, agudizada por el envejecimiento de la población chilena y la migración de

3 "Con respecto al extremo norte de Chile, uno de los aspectos de mayor significación, dice relación con que la Región de Arica y Parinacota es la única que en estos años ha disminuido su población, principalmente por la baja en los índices de actividad económica y por el aumento del desempleo. En contrario, Tacna ha experimentado un sostenido crecimiento poblacional producto de las franquicias especiales determinadas por el gobierno peruano, una creciente migración rural desde la sierra peruana a la ciudad y una política del estado peruano dirigida a poblar su región fronteriza con Chile" (ANEPE 2011). 
los jóvenes a otras regiones, especialmente al centro del país. En el caso de Tacna e Iquique, son dos ciudades que han crecido en los últimos censos gracias a la migración interna; la primera, proveniente de la sierra, Puno y Juliaca fundamentalmente (Berganza y Cerna, 2011); y en la segunda, proveniente del norte chico (III y IV regiones), la zona central de Chile y los departamentos fronterizos.

Respecto de Bolivia, la región en estudio colinda con los departamentos de La Paz, Oruro y Potosí, con los que comparte casi $600 \mathrm{~km}$ de frontera. Los departamentos bolivianos tienen la particularidad de concentrar casi la mitad de la población del país (4.166.787 habitantes), espacio en el que se incluye a la capital nacional; La Paz, y especialmente El Alto, son algunas de las ciudades de mayor crecimiento urbano en las últimas décadas. Dicha población se encuentra repartida en $305.761 \mathrm{~km} 2$ frente a solo $59.098 \mathrm{~km} 2$, sumado el actual Tarapacá y AricaParinacota. Es decir, aunque se trata de un área de alta concentración de población, especialmente en la capital altiplánica y en el Alto, disminuye en la medida que se acerca a la frontera con Chile. Esta zona cuenta con carreteras y tres pasos fronterizos que unen Tarapacá con las ciudades bolivianas y peruanas. Estos son el paso fronterizo o avanzada de Chacalluta-Santa Rosa, que une las ciudades de Tacna y Arica, Tambo Quemado, que une La Paz y Arica, y Colchane-Pisiga Bolivar, que une Oruro con Iquique (Figura 1).

En relación a la presencia de extranjeros fronterizos en el histórico Tarapacá, ha sido característica a lo largo de su historia desde su incorporación al Estado de Chile de acuerdo al tratado de 1883 y 1929 , respectivamente (Norambuena 2002; Tapia 2012, 2013). A partir de los años 90 del siglo XX hasta hoy, ha aumentado la llegada de extranjeros latinoamericanos a Santiago y las principales ciudades del país (Tapia 2012). Este último momento es el que ha desatado la "preocupación" por la migración fronteriza, especialmente de origen peruano, al centro de Chile, y el creciente interés investigativo por relevarlo. Este hecho ha llevado a ubicar a Santiago como la medida de la migración nacional, estableciendo - sin proponérselo- opacidad sobre los fenómenos que ocurren en los márgenes (Lube y Garcés 2012).

De acuerdo a los datos del cuestionado Censo $2012^{4}$, se observa que del total de extranjeros censados en la región de Tarapacá (22.165 personas), un $77 \%$ son de origen fronterizo, es decir 17.232 personas. De ese universo, el $48 \%$ corresponde a peruanos, el $36 \%$ es boliviano y un

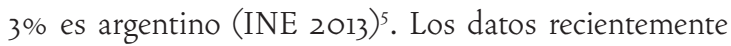
publicados por el Instituto Nacional de Estadísticas señalan que la población extranjera en Chile creció en un 160\% en el período 2002-2012, "es decir, si en el 2002 había 9 inmigrantes por cada 10.000 habitantes, el 2012 habría 24 inmigrantes por cada 10.000 habitantes" (El Periodista, 4 de septiembre 2014). Los datos ratifican la aceleración de la migración de mayoría sudamericana, entre los que destacan los de origen fronterizo y un aumento de otros grupos nacionales, entre ellos colombianos y españoles ${ }^{6}$. Según estimaciones del departamento de Extranjería y Migración, la población extranjera en Chile para el 2014 se estimaba en poco más de $440 \mathrm{mil}$ personas, de los cuales el $37,8 \%$ son de origen peruano, seguido por los argentinos con un $15 \%$, luego colombianos con $7,7 \%$ y en cuarto lugar los bolivianos con $5,1 \%$ (www.extranjeria.gob.cl).

Si bien los censos son la "fuente matricial" (Martínez 2008: 100) para el estudio de las migraciones, no son suficiente para conocer lo que sucede en una región fronteriza, por lo que es necesario revisar otras fuentes que nos den, al menos, una estimación de los movimientos de población. La XV Región de Arica y Parinacota y la I Región de Tarapacá son las regiones chilenas donde la entrada, circulación y el establecimiento de personas ha aumentado en las dos últimas décadas, porque son la puerta norte del territorio y porque el ingreso vía terrestre es uno de los más usados para entrar al país (OIM 2013b).

4 Los datos arrojados por el censo de 2012 no están disponibles porque en su aplicación hubo errores en la metodología.

5 Los censos tienen la limitación de remitir fundamentalmente al stocks, es decir, de los extranjeros presentes en un lugar y momento determinado en un territorio, su aplicación cada diez años impide conocer las variaciones por períodos más cortos u otros rasgos, como la situación jurídica (Tapia 2012).

6 Según datos de Extranjería, desde el año 2008 al 2013 los grupos que han aumento notoriamente en solicitudes de visas temporales, fuera de los de origen fronterizo, son españoles, colombianos, dominicanos y haitianos. Por ejemplo, en el caso de los españoles los permisos de residencia temporal pasaron de 712 el 2008 a 4918 el 2013, y en el caso de los colombianos el aumento fue de 4389 a 26627 solicitudes para los mismos años (www.extranjería.gob.cl). 
Por tanto, una fuente útil es el registro de entradas y salidas de chilenos, turistas, residentes y por convenio por pasos fronterizo de la Policía de Investigaciones de Chile (PDI) ${ }^{7}$, porque permite conocer el flujo de personas que ingresa y sale por la frontera. Esta base de datos es anual e incluye la nacionalidad y situación jurídica de quienes entran y salen por avanzada o puesto fronterizo. La ventaja de esta fuente es que da cuenta del movimiento de población en la frontera, es decir, de los extranjeros con distinta situación jurídica, pero no considera otros rasgos sociodemográficos como el sexo o la edad. La limitación de esta base de datos es el sobre registro de personas que cruzan diaria o semanalmente en más de una ocasión acogiéndose al convenio de Tacna y Arica de 2005. Por tanto, los datos dan cuenta del número de cruces y no del total de personas que ingresan para quedarse o personas que salen para no regresar.

Según la fuente de la Policía de Investigaciones señalada, el año 2000 entraban y salían por los distintos pasos fronterizos de la I Región de Tarapacá 424.885 extranjeros de origen peruano y boliviano. De ese total, 184.515 corresponden a ingresos de peruanos y bolivianos, y 224.426 a salidas de los mismos nacionales. Al comparar con los datos nacionales se aprecia que de ese universo, es decir, el total de entradas por los distintos pasos fronterizos a nivel nacional, los realizados por peruanos

7 Los extranjeros que entran a Chile en calidad de turista lo pueden hacer hasta por 90 días con pasaporte con fines de ocio, deportivo, recreo y gestiones familiares, entre otros. Los extranjeros por Convenio se refiere a las personas de origen peruano que ingresan por el paso de Chacalluta (XV Región), que se acogen al "Convenio de tránsito de personas en la zona fronteriza chileno-peruana de Arica y Tacna" firmado en 1983, y "Acuerdo para el Ingreso y tránsito de nacionales peruanos y chilenos en calidad de turistas con documento de identidad" de 2005 . Por este convenio, los chilenos y peruanos que viajen con salvoconducto, primero y a partir de 2005 con DNI o carnet de identidad, pueden permanecer por períodos de hasta siete días en el departamento de Tacna o en la provincia de Arica respectivamente. Este permiso impide realizar actividades con fines de lucro como trabajo temporal o permanente y permite viajar más allá de los límites señalados (www. extranjeria.gob.cl).

8 El año 2007 se creó la XV Región de Arica y Parinacota, hecho que dividió a la histórica región de Tarapacá en dos, por lo tanto, para mantener la base de comparación se sumaron los datos de la XV y I regiones para el año 2010.

9 Datos de la PDI entregados por sistema de transparencia de datos. y bolivianos por la región de Tarapacá representaron el $59,3 \%$ para ese año.

Para el año 2010, las entradas y salidas de extranjeros de origen fronterizo, peruanos y bolivianos, por los pasos fronterizos de la XV y I regiones se multiplicó en más de seis veces respecto del año 2000 , alcanzando un total de 2.734.079 (Cuadro $\left.\mathrm{N}^{\circ} 1\right)^{8}$. De ese universo, 1.550.115 de esas nacionalidades correspondió a ingresos y 1.506 .062 a salidas por ambas regiones. $9 \mathrm{Al}$ desagregar por nacionalidad y XV Región, creada el año 2007, se aprecia que los peruanos ingresan fundamentalmente por la región extrema donde se ubica el paso fronterizo de Chacalluta, por donde entró el 89,7\% del total de peruanos que ingresó al país ese año. Sin embargo, por la actual I Región de Tarapacá solo lo hizo el o,3\%, lo que sumado a la XV región da un $90 \%$ del total de peruanos que ingresa al país. La explicación de esta diferencia se debe a la existencia del convenio Tacna y Arica del año 2005, que permite el ingreso de peruanos a Arica hasta por siete días con documento de identificación. El convenio impide el ingreso hasta más allá del control fronterizo de Cuya ubicado a $115 \mathrm{~km}$ al sur de Arica. En el caso de los bolivianos se aprecia un ingreso más repartido entre ambas regiones, con un 59,3\% por la XV región de Arica y Parinacota, y 35,4\% por la I Región de Tarapacá respecto del total de bolivianos que ingresan al país.

Respecto de las salidas de la región de peruanos y bolivianos, se aprecia que retornan un poco menos de los que entran $(89,7 \%)$ y que la principal región de salida de peruanos (89\%) es la XV región, especialmente por Chacalluta, para el caso de peruanos, y Tambo Quemado (59\%) para los bolivianos. En la actual I Región, los bolivianos utilizan el puesto fronterizo de Colchane con un $35,4 \%$ de las entradas totales de los bolivianos que entran a Chile, y el $32,1 \%$ de las salidas. Dicho puesto fronterizo está ubicado a $236,4 \mathrm{~km}$ de Iquique y une a esta ciudad costera con Oruro, distante a más de $500 \mathrm{~km}$ de la frontera por la ruta nacional 4.

Según los datos de la PDI, lo que se aprecia es un fuerte movimiento de personas, peruanas y bolivianas, que cruzan constantemente la frontera en ambos sentidos. En el primer caso, prácticamente el 90\% del total de peruanos que ingresan y salen del país lo hacen por la XV región de Arica y Parinacota. Al revisar la situación jurídica se aprecia 


\begin{tabular}{|c|c|c|c|c|c|c|c|c|c|c|c|}
\hline \multirow[t]{2}{*}{ Totales } & \multicolumn{5}{|c|}{ Entrada (turistas, residentes y convenio) } & \multicolumn{5}{|c|}{ Salidas (turistas, residentes y convenios) } & \multirow{2}{*}{$\begin{array}{c}\text { TOTAL } \\
\text { Entradas y } \\
\text { salidas }\end{array}$} \\
\hline & peruanos & $\%$ & bolivianos & $\%$ & $\begin{array}{c}\text { Total } \\
\text { entradas }\end{array}$ & peruanos & $\%$ & bolivianos & $\%$ & Total salidas & \\
\hline Nacional & 1.251 .778 & 100 & 448.496 & 100 & 1.700 .274 & 1.214 .988 & 100 & 423.104 & 100 & 1.638 .092 & 3.338 .366 \\
\hline XV Región & 1.123 .314 & 89,7 & 264.671 & 59,0 & 1.387 .985 & 1.081 .423 & 89,0 & 256.145 & 60,5 & 1.337 .568 & 2.725 .553 \\
\hline I Región & 3.561 & 0,3 & 158.569 & 35,4 & 162.130 & 1.399 & 0,1 & 135.882 & 32,1 & 137.281 & 299.411 \\
\hline $\begin{array}{l}\text { Total XV y I } \\
\text { regiones }\end{array}$ & 1.126 .875 & 90 & 423.240 & 94 & 1.550 .115 & 1.082 .822 & 89 & 392.027 & 93 & 1.474 .849 & 3.024 .964 \\
\hline
\end{tabular}

Tabla 1. Entradas y salidas de peruanos y bolivianos por pasos fronterizos de las regiones XV y I en 2010.

Fuente: Datos obtenidos de la PDI por Ley de Transparencia. Elaboración propia

que, del total de peruanos que ingresaron el 2010 por dicha región, un 16,8\% lo hizo como turista, un 17,5\% eran peruanos residentes en Chile y un $54 \%$ se acogió al convenio de Tacna y Arica. Por tanto, el grueso de los peruanos que ingresa lo hace para permanecer por el día o varios días en la región (hasta siete según el convenio) y luego retornar.

\section{Frontera tarapaqueño-peruana}

La migración y la circularidad peruana entre Tacna y Arica. Para comprender cómo se configuran los patrones y tendencias de población de origen fronterizo en la región de estudio, es preciso tener en cuenta las reglas de entrada, tránsito y residencia existentes a nivel nacional y regional, así como los obstáculos y oportunidades que se abren para quienes cruzan la frontera. La primera nos remite al marco jurídico sobre extranjería, y las segundas, al mercado laboral regional y las posibilidades económicas que otorga el cruce fronterizo. Respecto del primero, el marco jurídico sobre migración y extranjería está dado por la Ley de Inmigración del año 1975, por el que las autoridades regionales gestionan los flujos migratorios, especialmente de origen sudamericano. Se trata de una las legislaciones más antiguas de América Latina, inspirada en la Doctrina de Seguridad Interior del Estado, para la cual el extranjero es visto como una amenaza (Stefoni 2011). Sin embargo, en los primeros años del siglo XXI se establecieron normativas específicas para las regiones extremas, como es el caso del convenio entre Tacna y Arica de 2005 que hemos mencionado más arriba.

En las últimas décadas los peruanos que llegan a la ciudad de Arica se acogen al convenio de Tacna y Arica, fenómeno facilitado por la cercanía entre ambas ciudades $(56,4 \mathrm{~km})$, las oportunidades económicas que ofrece la ciudad chilena y la posibilidad de conseguir un mayor rendimiento de los salarios debido al efecto que produce la brecha de desa- rrollo ${ }^{10}$. Aunque el convenio impide trabajar a quienes ingresan por el paso fronterizo de Chacalluta, es de público conocimiento que desde la puesta en vigencia del convenio de 1983, y el Acuerdo de Ingreso con Tarjeta de Identidad de 2005, las entradas a Chile por motivos laborales ha ido en aumento, como vimos en los datos de la PDI. Algunos cuentan con redes de apoyo previamente establecidas (amigos o conocidos), otros conocían la zona por turismo, vienen a través de agencias de empleo informales instaladas en Tacna, y el grueso cruza a probar suerte. Según la encuesta aplicada por Lube y Garcés, la mayoría inicia el proyecto de venir a Chile en soledad y otros vienen acompañados de familiares y conocidos (2013: 84). Así lo señalan las siguientes entrevistas:

"I: por primera vez como turista, exclusivamente como turista. E: ¿Y después el 2004?

I: ya vine, como también igual como para trabajar, vine para el problema familiar que tuve entonces. Dije 'la única opción que tenía' eran tres cosas: o regresarme a Lima, o irme para Bolivia, que también tenía opción para irme para allá, o venirme para acá a Chile. Entonces, como ya anteriormente había venido acá a Chile, entonces la única opción que era más cercana dije: me vengo para acá. Primero me vine el 2004, estuve así como ya quedándome, o sea buscando trabajo porque tenía que empezar de cero, a pesar

10 “... para el año 2011, el PIB per cápita de Bolivia es solo un 30\% del PIB per cápita de Chile, el de Ecuador es un 50\%, de Colombia, $59 \%$, Perú $60 \%$, República Dominicana $58 \%$ y el de Haití un magro 6,5\%. Por otra parte, Argentina presenta un PIB per cápita que es $3 \%$ más alto que Chile. Para que estos incentivos económicos (potenciales) a la migración se materialicen es necesario que las empresas y las familias estén dispuestas a contratar trabajadores extranjeros y que los migrantes puedan ingresar a Chile. Aunque los datos sobre diferencias salariales entre países de origen y países de destino son escasos, las diferencias de PIB per cápita son una aproximación al respecto" (Solimano et al. 2012: 28). 
de que no fue fácil, las primeras veces fue muy difícil, e incluso había momentos en que no trabajaba, entonces tenía que vender lo que yo tenía allá" (Mujer peruana, visa definitiva, entrevistada en Arica el 5 junio 2013 $)^{11}$

\section{"E: Usted señora, icuándo llegó a Arica?}

\section{I: En el año 94.}

E: ¿Y vino de paseo la primera vez?

I: Más o menos de paseo, una amiga me trajo acá y fuimos a trabajar.

E: iAh! pero sabía que podría trabajar.

I: Mi amiga me dijo, me trajo de Tacna, como ella ya venía uno no tiene ni idea, uno viene así como con mi ropita, lo puesto no más, como yo me fui a trabajar allá, como le digo, me vine así de pasada no más, y un día, dos días, me quedé" (Mujer peruana, sin papeles, entrevistada en Arica el 6 de junio 2013)

En Arica existe una demanda de trabajo para la agricultura, debido en parte a la modernización de la agricultura de los valles Lluta y Azapa colindantes a la ciudad de Arica y la ampliación de los espacios de cultivo en la región, que requieren gran cantidad de mano de obra en períodos de cosecha (González 1998a). Esa demanda se ha resuelto fundamentalmente con mano de obra peruana que se acoge al convenio mencionado, y población boliviana que ingresa por la frontera tarapaqueña con ese país. Las condiciones de trabajo y de vida que esperan a los fronterizos son precarias, puesto que la mayoría se incorpora a la economía sumergida, sin contratos ni cobertura de salud, motivados fundamentalmente por la posibilidad de ganar más dinero que en país de origen ${ }^{12}$. Como señaló un entrevistado:

"E: Y usted me decía que le pagan como ocho mil pesos el día, comparado con lo que ganan en Bolivia es muy diferente.

I: Mire, sisacamos un porcentaje de ocho mil pesos, te saldría algo de como 120 bolivianos, y en Bolivia puedes llegar a ganar 60 bolivianos como mucho" (Hombre boliviano, visa definitiva, entrevistado en Arica el 5 de julio 2012)

La posibilidad de cruzar a Chile, trabajar y regresar, ha sido una estrategia que ha permitido a la población, especialmente peruana, aumentar el rendimiento de los recursos obtenidos por su trabajo. La cercanía de ambas ciudades facilita la circulación, lo que produce un intenso ir y venir entre ambas ciudades, modelado por las oportunidades de tránsito establecidas por el convenio, y el efecto llamada del mercado laboral. Asimismo, los cruces van produciendo redes de parentesco y amistad que van alimentando este circuito migrante (Lube y Garcés 2013). Muchos de los peruanos que ingresan a Arica lo hacen en la modalidad de los siete días, es decir, trabajan de lunes a sábado, regresan ese día a Tacna y retornan a Arica el domingo o lunes a trabajar. Este tránsito ha crecido aceleradamente en los últimos años, convirtiendo al paso fronterizo de Chacalluta en el más cruzado del país, superando al aeropuerto de Pudahuel y el paso Los Libertadores.

En torno a la modalidad de las idas y vueltas, se ha generado una oferta de alojamientos precarios para quienes cruzan y no tienen donde quedarse. En el barrio aledaño al terminal internacional de Arica es posible alojar por muy poco dinero y volver a trabajar al día siguien$t \mathrm{t}^{13}$. Es una zona donde los recién llegados, hombres y mujeres peruanos, se instalan temprano en la mañana frente al terminal internacional a la espera de personas que los vengan a buscar para trabajar en distintas actividades (Lube et al. 2013). Quienes se insertan en el trabajo agrícola de los valles pueden acceder a alojamiento en el mismo lugar cuando la demanda y los empleadores lo ofrecen. En el caso de las mujeres peruanas, el servicio doméstico puertas adentro permite "ahorrar" los gastos de alquiler y comida. Como señaló una de las entrevistadas: "ya acá el almuerzo, la comida todo me lo ahorraba hasta la lavada de ropa porque ni siquiera lavaba yo $\mathrm{mi}$ ropa, la señora todo lo mandaba a la lavandería, o sea me compensaba bien" (Mujer peruana, sin papeles, entrevistada en Arica el 6 de junio de 2013).

11 Para la entrevistas se utiliza la letra E, que corresponde a entrevistador, y la I para informante.

12 Según el estudio de Lube y Garcés, el 60\% de los encuestados cruza a Arica por razones laborales debido a las escasas oportunidades económicas en su país o por estar desempleado al momento de venir a Chile (Lube y Garcés 2013: 85).

13 “- ¿Dónde duermes y comes?

- Tengo un alojamiento, por acá, cerca del cementerio. Comemos en la tía Lourdes, aunque es 'ahí no más' la comida. Tira a la olla un par de papas y listo, jajajajaja. La comida acá es más o menos. Allá es mejor. El picante no les queda igual.

- ¿Cuánto pagas en el alojamiento?

-Quinientos pesos" (Entrevista, 15 de abril 2011). 
Sin embargo, la mayoría de los peruanos que cruza bajo el sistema del convenio entre Tacna Arica no accede a contratos de trabajo, por lo que la maximización de las ganancias favorece especialmente a los empleadores, que evaden los gastos de cotizaciones previsionales y de salud. Así lo ha señalado el Servicio Jesuita Migrante de Arica, que ha llamado la atención sobre las condiciones de vida y de trabajo a la que acceden la población fronteriza: "Si a esto se suman los datos del estudio aplicado a 156 pequeños agricultores de Azapa (ISL, 2011), donde el $82 \%$ señala que contrata mano de obra extranjera porque es más rendidora, mayores razones habrá para dar empleo a personas de Bolivia y Perú. El problema de esto último es que en el mismo estudio solo el 1\% afirma tener a todo su personal contratado. El 83\% no tiene a ningún empleado con contrato" (Vicuña, 2 de julio 2012).

Las oportunidades laborales, las diferencias salariales y las posibilidades de circulación fronteriza en el marco del convenio de Tacna y Arica han facilitado un movimiento de población, para el caso peruano, que no tiene - en primera instancia- por objetivo central el establecimiento en la región. En los casos de personas que se han instalado en Arica, las entrevistas muestran una historia de continuos cruces, a veces por años, no solo entre Tacna y Arica, sino entre ciudades peruanas más nortinas y que con el tiempo se quedaron porque se casaron, formaron familias o porque accedieron a contratos de trabajo y consiguieron visa:

"Eh, al principio si porque nunca pensé quedarme acá, o sea no era mi meta quedarme acá, entonces trabajaba entre paréntesis como ilegal ya porque yo tenía solo una visa de turista, y hasta que tanto que salía a Tacna y volvía, y un día el de Investigaciones me dijo 'tú qué haces en Chile que tanto salidas', y yo le dije 'tengo a mi señora, tengo un niño', 'tienes 15 dias para casarte o si no te vai fuera del país. Y ahí opté por casarme, y ahi recién empecé a hacer mis papeles al segundo año, pero, pero dificultades no las tuve gracias a Dios. Yo soy de profesión costurero, en ese tiempo habian muchas empresas, estaba la Wrangler, estaban otras empresas grandes, donde mano de obra faltaban y siempre fui bien recibido, siempre fui buscado, por ese lado nunca tuve problema." (Hombre boliviano, visa definitiva, entrevistado en Arica el 5 de julio 2012).

Por tanto, la movilidad fronteriza entre Arica y Tacna se expresa fundamentalmente como circulación, debido al efecto estructurante del marco jurídico específico sobre el ingreso a la región y la acción del mercado laboral, que requiere mano de obra flexible y barata. De tantos cruces las personas aprenden a circular, a dónde buscar trabajo, dónde dormir y comer y cuándo regresar a Tacna, en síntesis en capital social (Lube y Garcés 2013) o en saber circular (Tarrius 2000). En algunos casos, estos movimientos dan como resultado el establecimiento definitivo, y en otros, se expresa como tránsito diario o semanal con fines laborales o comerciales de tipo formal e informal.

El rasgo común a estos movimientos, especialmente en los inicios de cada fase de movilidad es la marginalidad, la precariedad y la vulnerabilidad de los derechos a la que se ven expuestos los fronterizos. A pesar de las difíciles condiciones de vida y de trabajo que pueden encontrar, especialmente la población peruana, su persistencia se explica por los objetivos que trazan individual o familiarmente y por las necesidades que requieren cubrir de acuerdo a los ciclos de vida. Por tanto, los proyectos de circulación o migración explican en parte la "aceptación" de dichas condiciones, en tanto se supeditan a objetivos de bienestar o aspiraciones que no logran conseguir en sus lugares de origen. Tal como lo señaló uno de los entrevistados tacneños en esta investigación:

\section{"E: ¿Y por qué de Tacna venirse a Arica?}

V: como decía, si hay trabajo, por eso, por el trabajo más que todo, porque allá... por conocer también.

V: ¿Por qué usted trabajaba de administrador en un hotel en Tacna, y eso en términos económicos no le significaba tanto como para venir a trabajar la construcción o la chacra?

V: Si me daba, pero yo quería un poquito más porque siempre con los dichos del papá de la mamá; antes decían que cuando uno tiene que tener sus cosas, que esto, lo otro y yo quería mis cosas, quería mi casa, todo.

E: Y con el trabajo que tenía en Tacna, ¿era difícil conseguirlo? V: Dificil, dificil en la juventud más que todo, teniendo amistad allá en Tacna, y es más, para salir, para ir a diversión, y yo ya estando en Arica bajaba semanal" (Hombre peruano, visa definitiva, entrevistado en Iquique el 20 de diciembre de 2012).

La confluencia entre las necesidades de los fronterizos, los requerimientos de un agro que se moderniza, la existencia de una economía sumergida, la demanda de mano 
de obra en oficios de baja calificación y la brecha salarial entre países, estructuran los movimientos de población y circulación favorecidos por los acuerdos jurídicos sobre ingreso y tránsito de personas. Cabe destacar que, así como cruzan peruanos a la región, también lo hacen chilenos hacia Perú, especialmente a Tacna, pero con fines totalmente distintos. Los chilenos viajan fundamentalmente a comprar, a turismo médico y ocio.

\section{Frontera tarapaqueño-boliviana}

Durante el siglo XX, y a excepción del ciclo salitrero, la migración fronteriza boliviana se dirigió fundamentalmente a Argentina. Estos movimientos tuvieron como destino inicial las zonas fronterizas, especialmente el noreste argentino, que atrajo a población rural boliviana a la actividad en torno a la caña de azúcar — la zafra - y la explotación de tabaco. Los factores fueron "salarios más altos y los cambios sobrevenidos por la Guerra del Chaco (1932-35) en la sociedad boliviana, la reforma agraria y la agitación política, motivaron la salida de mano de obra" (Balán 1990: 272). A mediados del siglo XX, la migración se amplió hacia Mendoza y Jujuy para cubrir las necesidades de mano de obra de la actividad vitivinícola. A partir de los años 60 de la misma centuria, debido a los cambios tecnológicos en el agro y las crisis económicas de los empleos rurales, la migración boliviana se dirigió hacia Buenos Aires, donde la ciudad amplió la demanda de trabajo en oficios de poca calificación. Estos movimientos fueron temporales y cíclicos y contenían el retorno frecuente a Bolivia, combinando estancias y tiempos entre origen, tránsito y destino (Hinojosa 2000; Benencia 2004; Cortés 2004) ${ }^{14}$.

De modo que el destino migratorio preferente de Bolivia durante el siglo XX fue Argentina, por tanto el interés por llegar a Tarapacá es relativamente reciente. Como señalamos, el marco jurídico que regula el tránsito de personas entre Chile y Bolivia es la ley de Extranjería de 1975. Sin embargo, el año 2009 entró en vigor el Acuerdo de Residencia de los Nacionales de los Estados Partes del MERCOSUR Bolivia y Chile. En base a este acuerdo

14 Según datos de la OIM, el año 2010 el número de bolivianos en Argentina ascendía a 345.272 personas, lo que corresponde al $48,9 \%$ del total de bolivianos/as en el exterior. Le sigue España con 222.497 personas, con datos de 2009, y Estados Unidos con 99.210 personas, según datos del 2010 (Pereira 2011:36). los nacionales de Argentina, Bolivia, Brasil, Paraguay y Uruguay se les pueden otorgar visaciones de residencia temporaria por un año, prorrogable por igual período sin necesidad de contar con un contrato de trabajo al momento de solicitar la visa (Oficio Circular $\mathrm{N}^{\circ} 26465$, de Subsecretario del Interior, del cuatro de diciembre de 2009). Sin embargo, de acuerdo a la información aportada por los informantes claves, ha sido frecuente que los bolivianos de origen aymara establecidos en la frontera crucen la frontera por distintos medios - a pie, en camión o autos - por pasos no habilitados sin presentar papeles en los puestos fronterizos. Así lo señaló uno de los informantes claves de esta investigación:

"Hace tiempo atrás tuve una conversación con gente de Colchane, con el alcalde, y un grupo de personas del consejo y ellos no reconocen la frontera. Es algo como impuesto por el Estado de Chile que ellos no respetan, porque ellos transitan en forma libre, entonces no entienden porque no pueden o porque no tienen un trato preferencial. En este caso, que no se da la legislación. El problema es que estas personas, por la cercanía de los pueblos, hay un intercambio comercial grande, sin embargo Chile tiene sus exigencias fitosanitarias que impiden a éste traer o comprar cualquier tipo de algunos productos, leches, carnes..." (Comisario, Policía de Investigaciones, Chile).

Estas prácticas fronterizas no solo ocurren en el norte de Chile sino también en la zona central, donde se detectan situaciones similares vinculadas a los desplazamientos tradicionales de pastores y baqueanos, cuyas raíces se hunden en la Colonia y que persisten en la actualidad (Hevilla 2007). En caso estudiado, los objetivos para este tipo de cruce han sido diversos, entre ellos actividades económicas informales relacionadas con el pastoreo o el trabajo agrícola en los valles interiores de la región, hasta actividades ilícitas como el contrabando de drogas o robo de camionetas (Corder y Ruiz-Tagle 2013).

\section{Aymaras bolivianos históricos y migrantes recien- tes}

Respecto de la presencia de población boliviana, es posible distinguir dos tipos de movimientos de población en la región; por un lado, una de tipo eminentemente rural e indígena que posee una profundidad histórica mayor que la coyuntura reciente (González 1998a, 1998b; Gundermann y González 2008); y otra más actual, que tiene 
como destino las ciudades costeras de Tarapacá, Arica e Iquique. La primera tiene sus antecedentes en los años 50 del siglo pasado, especialmente notoria en el norte de la región involucrando a valles precordilleranos, el altiplano y las zonas fronterizas con Bolivia y a la población aymara de la zona. El auge de Arica en el marco del impacto que produjo la creación de la Junta de Adelanto (Quiroz et al. 2011), la habilitación de nuevos espacios de cultivo y la colonización de los valles de Lluta y Azapa mediante el sistema de asentamientos y cooperativas que se tradujo en un foco de atracción migratoria de los distintos pisos ecológicos regionales (González 1998a, 1998b). Poco a poco, la población aymara boliviana ubicada en el sector altiplánico fronterizo fue atraída por la demanda de mano de obra para faenas agropecuarias en las comunidades chilenas altiplánicas o precordilleranas. En estos movimientos participaron pastores aymaras bolivianos que fueron "bajando" escalonadamente hasta llegar en muchos casos a los valles medios y bajos, cercanos a la ciudad de Arica (González 1998a: 8-9).

Entrados los años 70, las tierras de cultivo de los valles de Lluta y Azapa fueron parceladas y vendidas entre chilenos, aymaras y no aymaras. De ese grupo, los aymaras bolivianos fueron los que tuvieron menor acceso a la propiedad de la tierra debido a la condición de extranjeros y a la imposibilidad jurídica de comprar tierras por ser extranjeros. Sin embargo, los aymaras bolivianos accedieron a la tierra a través de la modalidad de mediería y custodia. La primera modalidad consistía en convenios que implicaban el pago de una renta, normalmente en cosechas, correspondiente a la mitad de la producción (González 1998b: 14). La segunda corresponde a un acuerdo informal, casi siempre verbal, sobre cuidado y mantención de un predio a cambio de poder explotarlo, esta práctica fue usada especialmente entre parientes (González 1998b: 14). Por ambos sistemas se explica el relevo de aymara chilenos por aymara bolivianos que se produjo en los valles bajos, medio alto andinos, especialmente en el norte de la región de estudio.

En la mayoría de los casos, la motivación para la migración escalonada o directa hasta Arica fue fundamentalmente económica, en un contexto de crisis de la agricultura y el pastoreo en la zona fronteriza boliviana. Estos factores explican la migración temporal de aymaras bolivianos a la zona altiplánica y la precordillera, la circulación en tem- poradas de cosechas y la llegada a Arica para incorporarse progresivamente en el comercio y en el servicio doméstico (González 1998a, 1998b). Así lo señaló un residente boliviano que lleva en Arica más de 20 años:

"I: Mira, la actividad en que trabajan la mayoría es en el agro, o sea en el valle de Azapa. La mayoría es agricultor.

E: incluso la gente que lleva mucho tiempo? ¿o la gente que llega? I: La gente que lleva mucho tiempo la mayoría es agricultor, y los nuevos que llegan también son agricultores, son muy pocos los que están dentro de la ciudad de taxista, que son comerciantes, que trabajan en el agro hay pocos, pero lo que hay por ejemplo restaurantes por ejemplo, ahí abrieron restaurantes que están dueñosya.

E: Ellos ya tienen un papel de residencia.

I: Sí, sí.

E: Y me decían que en Azapa hay propietarios de chacras que son bolivianos.

I: En sí los hijos, lo que pasa es que ahí, la ley dice de que un extranjero no puede comprar tierras en áreas rurales, solamente en área urbana no más" (Residente boliviano en Arica).

En el sur de la región, el cultivo de hortalizas y productos agrícolas ha servido para abastecer el crecimiento sostenido de la ciudad de Iquique, que demanda este tipo de productos. La práctica de explotación de la tierra por el sistema de mediería o de custodia ha sido un mecanismo que ha permitido incorporar a aymaras bolivianos en los valles andinos, hecho que sostuvo la migración de aymaras chilenos hacia las ciudades de Arica e Iquique. Esta combinación de migración fronteriza y rural/urbana dio lugar al establecimiento multilocal de las familias bolivianas en ambos países, y entre aymaras chilenos y bolivianos en los valles y las ciudades. Estos movimientos de población se registran desde los años 80 a la fecha y explican en gran parte el crecimiento de las áreas urbanas como es el caso de Iquique, especialmente de Alto Hospicio, espacio que en pocos años pasó de ser una zona periurbana con fines agrícolas (Guerrero 1995) a convertirse en una comuna urbanizada con casi 90 mil habitantes el 2012, según las estimaciones del INE.

Así, la relación con el espacio fronterizo ha permitido a los aymaras de uno y otro lado tomar las oportunidades de la integración económica y comercial de las regiones del norte desde los años 80 a la fecha, especialmente en rubros como el comercio y el transporte de productos agrícolas. Se trata 
de corrientes intrarregionales y fronterizas que han mantenido, por un lado, la relación entre la agricultura y ganadería de subsistencia, y la modernización de los cultivos de Azapa y Lluta en el caso de Arica, por otro (González 1998a, 1998b; Gundermann y González 2008).

El segundo momento de la migración y circulación de bolivianos a la región se registra desde los años 90 a la fecha y tiene un carácter más urbano, y se inscribe en el contexto de crecimiento de la migración sudamericana en el país (Tapia 2012). Es decir, son personas que buscan llegar a las ciudades costeras, especialmente a Iquique. De acuerdo a las indagaciones hechas en el trabajo de campo la población boliviana, ingresa en calidad de turista por el paso fronterizo de Colchane para trabajar tres meses $(90$ días que permite el ingreso como turista) en la economía informal o sin contratos de trabajo, para luego regresar a Bolivia, "hacer frontera" y volver a entrar por un tiempo similar (Tapia y Ramos 2013).

En otros casos se produce el retorno a Bolivia hasta que surja una nueva necesidad. Según algunos estudios de nivel local, los inmigrantes bolivianos vienen por temporadas, principalmente provenientes de los departamentos bolivianos fronterizos de La Paz, Potosí y especialmente de Oruro. La mayoría mantiene relación con su lugar de origen regresando a lo menos una vez al año y manteniendo contacto telefónico con sus familiares. Los oficios que desempeñan son fundamentalmente en actividades agrícolas para los que tienen asentamiento rural. Para quienes llegan, especialmente a Iquique, los oficios realizados son fundamentalmente de trabajadora doméstica, cocinerías y en el comercio formal o informal. Quienes llevan más tiempo y han accedido a contratos laborales y visas ad hoc se insertan en diversos oficios, especialmente en el servicio doméstico, como dependientes en ferias rotativas, en trabajos de albañilería y en atención de locutorios, entre otros.

Paralelo a este movimiento, cuyo fin en ocasiones ha dado como resultado el establecimiento en la región o la residencia multilocal entre ambos países y espacios (rural/ rural y rural urbano), se registra otro movimiento de población más reciente ${ }^{15}$. Se trata del impacto que ha tenido la creación de la Zona Franca de Iquique (ZOFRI) en el vínculo comercial de Tarapacá con Bolivia. La ZOFRI fue creada en 1975 con el objeto de reimpulsar la economía de Iquique luego de una larga depresión económica tras el fin del ciclo salitrero (González 1985; Fuentes 2007). Desde su fundación ha estimulado el desarrollo de la región y promovido la integración económica de Chile con el mundo y los países vecinos, fenómeno que se intensificó a partir del retorno a la democracia (1990). En este contexto, la actividad de la ZOFRI ha sido central para vincular a la región con Bolivia, puesto que el principal destino de las importaciones que entran a la ZOFRI se dirigen a ese país (ZOFRI 2006). Asimismo, el comercio al detalle y mayorista tiene entre sus principales destino el país vecino, lo que se ha traducido en un foco de atracción de comerciantes que llegan hasta Iquique para comprar, permanecer unos días y regresar cargados de productos a las principales ciudades bolivianas (Pereira y Uribe 2010). Estos movimientos de población han dado lugar a un trasiego fronterizo que se traduce en una circulación constante de comerciantes, que ha marcado una impronta de algunos sectores de la ciudad. Uno de ellos es el surgimiento del barrio boliviano de Iquique, que se ha constituido en plataforma de apoyo para quienes vienen a comerciar, con la instalación de servicios de alojamiento, comida, buses y taxis.

\section{$\bullet$ Conclusiones}

En el contexto del auge migratorio fronterizo iniciado en los años 90, los movimientos de población se explican fundamentalmente por demanda laboral tarapaqueña, las normas específicas que regulan el tránsito y permanencia de los extranjeros de origen limítrofe - notorio en el caso de Tacna y Arica- y por las brechas de desarrollo a uno y otro lado del linde, lo que ha convertido a la frontera en un recurso. Es decir, los fronterizos cruzan porque encuentran oportunidades laborales que no hay en sus países, o al menos no en las condiciones que esperan. Aunque la precariedad y la vulneración de derechos son frecuentes, esas condiciones son "admitidas" porque permiten cumplir con objetivos y metas trazadas en la partida, y en tanto se definen como temporales o hasta que no encuentran mejores opciones para el establecimiento o el retorno. Por tanto, la posición que alcanzan los peruanos y bolivianos que llegan a la región, para cir-

15 Aunque no contamos con datos censales de 2012, la información de los censos anteriores $(1992,2002)$ señala una tendencia a la feminización de los flujos fronterizos, hecho que coincide con la tendencia nacional (Stefoni 2009; Tapia 2012). 
cular (ir y venir) o para quedarse de manera temporal o definitiva, ha estado marcada por el nivel de aceptación de las condiciones de trabajo y las oportunidades que van encontrando en el camino. Es decir, por el escaso poder de negociación de quienes llegan a la región y por afán de cumplir con compromisos u objetivos trazados en origen o replanteados una vez conocido el territorio.

Así, la articulación entre frontera, mercado laboral y marco jurídico viene estructurando patrones migratorios y de movilidad fronteriza particulares en Tarapacá, de acuerdo al campo de posibilidades que se abre para ellos por el solo hecho de cruzar el linde. La idea de la frontera como recurso ha modelado formas de circulación cuyo objetivo final no es necesariamente el establecimiento, y que tiene al retorno como parte central de los proyectos de cruce, lo que da lugar a modos de vida binacional, especialmente entre las ciudades de Tacna y Arica.

En un contexto de desigualdades de desarrollo, agravado por la marginalidad de las regiones en estudio - especialmente en el caso de los departamentos fronterizos bolivianos-, la posibilidad de venir a Tarapacá para alcanzar objetivos de corto y largo plazo, han convertido el espacio fronterizo en un espacio de circulación que ha crecido fuertemente en los primeros años del siglo XXI. La frontera tarapaqueña separa mercados laborales precarizados y une a quienes demandan mano de obra barata y flexible con quienes están "dispuestos" a aceptar ciertas condiciones de trabajo. Así el cruce, las idas y venidas o las permanencias temporales o definitivas, no son una excepción en la región sino parte de un saber circular de quienes quieren cruzan para obtener un mayor rendimiento de los recursos y de quienes ya conocen las "ventajas" de su traspaso. En el caso de los aymaras de origen boliviano no ha supuesto una difi- cultad, porque en muchos casos la cruzan a pie y van y vuelven, porque la frontera históricamente no ha sido concebida como una barrera.

De este modo el trasiego de personas en la frontera ha configurado un espacio transfronterizo que une y vincula a comunidades y personas que la transitan, la cruzan y habitan más allá de las barreras y los litigios entre países. Esta circulación, especialmente entre Tacna y Arica se constituye en un capital migratorio o saber circular, que se difunde entre las redes familiares, de amigos y paisanos, lo que permite replicar los cruces.

Así, de acuerdo a los aportes del transnacionalismo y la geografía social francesa sostenemos que, desde los años 90 , se ha desarrollado un espacio circulatorio en el extremo norte de Chile - Tacna y Arica- y los departamentos fronterizos aledaños, que se intensifica entrado el siglo XXI y todo indica que seguirá creciendo. Esta realidad específica obliga a repensar las categorías de análisis de los estudios migratorios y los estudios fronterizos, en tanto la movilidad en la frontera posee un anclaje más notorio al territorio que en el caso de los movimientos internacionales. Por tanto, la frontera y la movilidad son dos aspectos íntimamente conectados, y la consideración de la perspectiva de quienes la cruzan, la pasan y circulan invita a despegarnos del nacionalismo metodológico y a mirar la transfrontericidad que producen estos movimientos. Así, la revisión de las categorías de análisis a partir de investigaciones concretas y situadas permite repensarlas y ajustarlas a la realidad específica, en este caso el de las regiones fronterizas.

Agradecimientos Este trabajo se basa en los resultados de investigación del Proyecto FONDECYT 11110096.

\section{* Referencias Citadas}

AMILHAT-SZARY, A. L. 2013. Cultura de fronteras. En Frontera, fronteras, B. E. Nates (Ed.), pp. 43-6o. Universidad de Caldas, Manizales.

AMILHAT-SZARY, A. L. y L. ROUVIÈRE. 2009. Des dynamiques transfrontalières au bilan d'aménagement du territoire: Innovations et blocages dans les Andes centrales (Chili-PérouBolivie). Mosella, No Especial "Fronteras y desarrollo".
ANEPE. 2011. Chile y su población. Http://www.temas. $\mathrm{cl} / \mathrm{p}=12381$

BALÁN, J. 1990. La economía doméstica y las diferencias entre los sexos en las migraciones internacionales: un estudio sobre el caso de los bolivianos en la Argentina. Estudios Migratorios Latinoamericanos 15-16: 269-292. 
BARDAJÍ, F. 2006. Literatura sobre inmigrantes en España. Ministerio del Trabajo y Asuntos Sociales, Madrid.

BELlO, D. 2012. La Triple Frontera del Paraná (Paraguay-BrasilArgentina): Condiciones endógenas institucionales e ilegalidad. RIL, Santiago de Chile.

BENEDETTI, A. y E. SALIZZI. 2011a. Frontera y movilidad. Aproximación al caso argentino-boliviano. Revista do Centro de Educacao e Letras 13 (1): 55-80.

BENEDETTI, A. y E. SALIZZI. 2onıb. Llegar, pasar, regresar a la frontera. Aproximación al sistema de movilidad argentinoboliviano. Transporte y territorio 4: 148-179.

BENENCIA, R. 2004. Familias bolivianas en la producción hortícola de la provincia de Buenos Aires. Proceso de diseminación en un territorio transnacional. En Migraciones Transnacionales. Visiones de norte y Sudamérica, A. Hinojosa (Ed.), pp. 201-229. Plural Editores, La Paz.

BERGANZA, I. y M. CERNA. 2011. Dinámicas migratorias en la frontera Perú-Chile. Arica, Tacna e Iquique. Fondo Editorial de la Universidad Ruiz de Montoya, Lima.

BRYCESON, D. y U. VUORELA. 2002. The Transnational family: New European frontiers and global networks. Berg Publishers, Oxford.

BUSTAMANTE, J. 1997. El marco teórico-metodológico de la "circularidad migratoria": su validación empírica Sociológica. Revista de pensamiento social 2: 77-119.

CAMPERO, F. 1999. Bolivia en el siglo XX. La formación de la Bolivia Contemporánea. Harvard Club de Bolivia, La Paz.

CANALES, A. 1999. Periodicidad, estacionalidad, duración y retorno. Los distintos tiempos en la migración México-Estados Unidos. Papeles de Población 22: 11-4.

CORDER, A. y V. RUIZ-TAGLE. 2013. Infracciones penales en espacios transfronterizos. El narcotráfico en la provincia del Tamarugal, Chile. Estudios Fronterizos 14 (27): 31-63.

CORTÉS, G. 2004. Una ruralidad de la ausencia. Dinámicas migratorias en los valles interandinos de Bolivia en un contexto de crisis. En Migraciones Transnacionales. Visiones de norte y Sudamérica, A. Hinojosa (Ed.), pp. 167-199. Plural Editores, La Paz.

2009. Migraciones, construcciones transnacionales y prácticas de circulación. Un enfoque desde el territorio. Párrafos geográficos 8 (1): 35-53.

CROSSETTE, B. 2011. Estado de la población mundial 2011: 7 mil millones de personas, su mundo, sus posibilidades. Fondo de Población de las Naciones Unidas (UNFPA), New York.

CUEVA, M. 2005. Frontera y representaciones fronterizas: aproximaciones comparativas entre Estados Unidos y América Latina. Estudios Fronterizos 6 (11): 9-38.

DONZELLI, S. 2014. Migration, the Global South, and Migrant Women Workers in the Field of Border Studies: Theoretical Approaches, Themes of Inquiry, and Suggestions for Future Work. Migration Literature Review 3: 2-51.

DURAND, J. 2006. Los inmigrantes también emigran: la migración de retorno como corolario del proceso REMHU. Revista Interdisciplinar da Mobilidade Humana 26-27: 167-189.

FAIST, T. 2000. Transnationalization in international migration: implications for the study of citizenship and culture. Ethnic and Racial Studies 23: 189-222.

GARDUÑO, E. 2002. Antropología de las fronteras, la migración y los procesos transnacionales. Frontera Norte 15 (30): 65-89.

GLICK SCHILLER, N. 2008. Nuevas y viejas cuestiones sobre localidad: teorizar la migración transnacional en un mundo neoliberal. En Nuevos retos del transnacionalismo en el estudio de las migraciones, C. Solé, S. Parella y L. Cavalcanti (Eds.), pp. 23-45. Ministerio de Trabajo e Inmigración, Madrid.

GONZÁLEZ, H. 1998a. Características de la inserción de aymaras chilenos y bolivianos en el área de Arica. Taller de Estudios Andinos (TEA), Arica.

1998b. La posición de aymaras chilenos y bolivianos en la estructura de tenencia de la tierra de los valles de Lluta y Azapa. Taller de Estudios Andinos (TEA), Arica.

GONZÁLEZ, S. 1985. ZOFRI: un enclave comercial. Cuaderno de Investigación Social Centro de Información de Recursos Naturales (CIREN) 14: 5-32.

2004. Pax castrense en la frontera norte. Una reflexión en torno a la post-guerra del Salitre: el conflicto por Tacna-Arica y Tarapacá. Universum 19: 28-57.

2008. La llave y el candado: el conflicto entre Perú y Chile por Tacna y Arica (1883-1929). LOM Ediciones, Santiago de Chile.

GUERRERO, V. 1995. De parcela a comuna. La producción de espacio social en Alto Hospicio. Revista de Ciencias Sociales 5: 18-40.

GUNDERMANN, H. y H. GONZÁLEZ. 2008. Pautas de inte- 
gración regional, migración, movilidad y redes sociales en los pueblos Indígenas de Chile. Universum 23 (1): 82-115.

HEVILLA, M. C. 2007. Movilidades y construcciones de nuevas territorialidades en la frontera chileno-argentina. Http:// www.ub.edu/geocrit/sn/sn-24522.htm.

HEYMAN, J. 2012. Construcción y uso de tipologías: movilidad geográfica en la frontera México-Estados Unidos. En Métodos cualitativos y su aplicación empírica. Por los caminos de la investigación sobre migración internacional, M. Ariza y L. Velasco (Eds.), pp. 419-454. Instituto de Investigaciones Sociales, Universidad Autónoma de México, Colegio de la Frontera Norte, México D.F.

HINOJOSA, A. 2000. Idas y venidas. Campesinos tarijeños en el norte argentino. Programa de Investigación Estratégica en Bolivia (Fundación PIEB), La Paz.

HOCHSCHILD, A. R. 2000. Las cadenas mundiales de afecto y asistencia y la plusvalía emocional. En En el límite. La vida en el capitalismo global, W. Hutton, A. Giddens y M. L. Rodríguez (Eds.), pp. 187-208. Tusquets Editores, Barcelona.

INE. 2010. Compendio Estadístico. 1.2. Estadísticas demográficas. http://www.ine.cl/canales/menu/publicaciones/compendio_estadistico/pdf/2010/1.2estdemograficas.pdf

2013. Resultados finales Censo 2012. http://www.censo.cl/

JOHNSON, C., R. JONES, A. PAASI, L. AMOORE, A. MOUNTZ, M. SALTER y C. RUMFORD. 2011. Interventions on rethinking 'the border' in border studies. Political Geography 30: 61-69.

JOHNSON, H. L. 2013. The Other Side of the Fence: Reconceptualizing the "Camp" and Migration Zones at the Borders of Spain International. Political Sociology 7: 75-91.

LEVITT, P. 2011. A transnational gaze. Migraciones Internacionales 6(1): 9-44.

LUBE, M. y A. GARCÉS. 2012. Mujeres peruanas en las regiones del norte de Chile: Apuntes preliminares para la investigación. Estudios Atacameños 44: 5-34.

2013. Circuitos migrantes. Itinerarios y formación de redes migratorias entre Perú, Bolivia, Chile y Argentina en el norte grande chileno. Papeles de Población 19 (78): 65-110.

LUBE, M., O. HEREDiA, A. MUÑOZ, G. RiQUELME y F. VALDEBENITO. 2013. Experiencia migrante y apropiaciones espaciales: una etnografía visual en las inmediaciones del Terminal Internacional de Arica (Chile). Revista de Estudios Sociales 48: 166-175.

MALLIMACI, A. I. 2012. Movilidades y permanencias. Repensando la figura del movimiento en las migraciones. Temas de Antropología y Migración 3: 77-92.

MANCANO, B. 2010. Movimientos socioterritoriales y movimientos socioespaciales. Contribución teórica para una lectura geográfica de los movimientos sociales. En http:// www.acaoterra.org/IMG/pdf/Movimientos-socioterritoriales-y-movimientos-socioespaciales.pdf

MARCU, S. 2013. La movilidad transfronteriza de rumanos en España en tiempos de crisis. Revista Internacional de Sociología 71 (1): 115-141.

MARTÍNEZ, J. 2008. Medición e información sobre la migración internacional a partir de los censos: Lecciones, desafíos y oportunidades. Notas de Población 88: 97-133.

MASON, J. 2006. Mixing methods in a qualitatively driven way. Qualitative Research 6 (1): 9-25.

MEDINA, E. 2006. Aportaciones para una epistemología de los estudios sobre fronteras internacionales. Estudios Fronterizos 7 (13): 9-27.

MINISTERIO DE INTERIOR. DEPARTAMENTO DE EXTRANJERÍA. www.extranjeria.gob.cl

MORALES, A. 2010. Desentrañando fronteras y sus movimientos transnacionales entre pequeños estados. Una aproximación desde la frontera Nicaragua-Costa Rica. En Migraciones y frontera. Nuevos contornos para la movilidad internacional, M. E. Anguiano y A. M. López (Eds.), pp. 185224. Icaria, Barcelona.

NORAMBUENA, C. 2002. Migraciones limítrofes. Chile 1865-1960. En Historia de las migraciones limítrofes en el Cono Sur de América. Argentina, Bolivia, Brasil, Chile, Paraguay y Uruguay, Volumen II: Bolivia, Chile, Paraguay y Uruguay, H. Asdrúbal (Ed.), pp. 25-90. Instituto Panamericano de Geografía e Historia, México D.F.

NUÑEZ, A. 2011. Territorios fronterizos, territorios aislados: conceptos dinámicos de construcción histórica (procesos de significación). En El aislamiento geográfico: ¿Problema u oportunidad?, F. Arenas, A. Salazar y A. Núñez, (Eds.), pp. 140-157. Instituto de Geografía, Pontificia Universidad Católica, Santiago de Chile. 
NUÑEZ, A., R. SÁNCHEZ y F. ARENAS. 2013. Fronteras en movimiento e imaginarios geográficos. La Cordillera de los Andes como espacialidad sociocultural. RIL Editores, Santiago de Chile.

OIM. 2013a. Informe sobre las migraciones en el mundo 2013. El bienestar de los migrantes y el desarrollo. Organización Internacional para las Migraciones (OIM), Ginebra.

2013b. Perú, estadísticas de la emigración internacional de peruanos e inmigración de extranjeros 1990-2012. Organización Internacional para las Migraciones (OIM), Lima.

2013c. Tendencias migratorias en la región. Http://argentina.iom.int/ro/es/node/181

PAASI, A. 2011. A Border Theory: An unattainable dream or a realistic aim for border scholars? En The Ashgate Research Companion to Border Studies, D. Wastl-Walter (Ed.), pp. 11-32. Ashgate, London.

PARELLA, S. 2013. Una aproximación al estudio empírico del retorno desde una perspectiva transnacional: El caso boliviano en España. En Políticas públicas, migración familiar y retorno de la población migrante latinoamericana en Cataluña: una perspectiva transnacional, C. Pedone y S. Gil (Eds.), pp. 20-26. Consorci Institut d'Infància i Món Urbà, Barcelona.

PAYÁ, M. C. 2007. De los espacios de relación a las redes de inclusión: una vía de promoción de las mujeres inmigrantes. Ministerio de Trabajo y Asuntos Sociales, Madrid.

PEREIRA, R. 2011. Perfil migratorio de Bolivia. Organización Internacional para las Migraciones (OIM), Buenos Aires.

QUIROZ, D., A. DÍAZ, L. GALDAMES y R. RUZ. 2011. Campesinos andinos y políticas agrarias durante la Junta de Adelanto de Arica (Azapa, Lluta y la precordillera, 1959-1976). Idesia 29 (2): 157-168.

RIBAS, N. 2011. Río Bravo Mediterráneo. Las regiones fronterizas en la época de la globalización. Edicions Bellaterra, Barcelona.

SASSEN, S. 2007. Una sociología de la globalización. Katz, Buenos Aires.

SASSONE, S. 2010. Cruzar y vivir la frontera entre Bolivia y la Argentina. Entre el estado y el capital espacial del migrante. En Migraciones y frontera. Nuevos contornos para la movilidad internacional, M. E. Anguiano y A. M. López (Eds.), pp. 225-257. Icaria, Barcelona.

SINATTI, G. 2008. Migraciones, transnacionalismo y locus de investigación: multi-localidad y la transición de 'sitios' a 'cam- pos'. En Nuevos retos del transnacionalismo en el estudio de las migraciones, C. Solé, S. Parella y L. Cavalcanti (Eds.), pp. 93-112. Ministerio de Trabajo e Inmigración, Madrid.

2010. 'Mobile Transmigrants' or 'Unsettled Returnees'? Myth of Return and Permanent Resettlement among Senegalese Migrants Population. Space and place 17: 153.

SOLIMANO, A., V. MELLADO, C. ARAYA, S. LAHOZ y Y. OCÓN. 2012. Incorporación laboral de los migrantes en la Región Metropolitana de Chile. Organización Internacional para las Migraciones (OIM), Santiago de Chile.

SOLÍS, M. 2009. Trabajar y vivir en la frontera: Identidades laborales en las maquiladoras de Tijuana. Colegio de la Frontera Norte (COLEF), Tijuana.

STEFONI, C. 2009. Inmigrantes en Chile. Una integración diferenciada al mercado laboral. En Migración y politicas sociales en América Latina, P. Fischer-Bollin (Ed.), pp. 81-108. Fundação Konrad Adenauer, Rio de Janeiro.

2011. Ley y política migratoria en Chile. La ambivalencia en la comprensión del migrante. En La construcción social del sujeto migrante en América Latina. Prácticas, representaciones y categorías, B. Feldman-Bianco, L. Rivera Sánchez, C. Stefoni, M. I. Villa Martínez (Comps.), pp. 79-109. CLACSO - FLACSO - Universidad Alberto Hurtado, Santiago de Chile.

TAPIA, M. 2012. Frontera y migración en el Norte de Chile a partir del análisis de los censos de población. S. XIX y XXI. Revista Geografía Norte Grande 52: 177-198.

2013. Migración y movilidad de los trabajadores fronterizos en Tarapacá durante el ciclo del nitrato. 1880-1930. En La sociedad del salitre: protagonistas, migraciones, cultura urbana $y$ espacios públicos, 1870-1940, S. González (Ed.), pp. 163-194. Universidad Arturo Prat, Iquique, RIL Editores, Santiago de Chile.

TAPIA, M. y R. RAMOS. 2013. Mujeres migrantes fronterizas en Tarapacá a principios del siglo XXI. El cruce de las fronteras y las redes de apoyo. Polis. Revista Latinoamericana 12 (35): 229257.

TARRIUS, A. 2000. Leer, describir, interpretar las circulaciones migratorias: conveniencia de la noción de 'territorio circulatorio'. Los nuevos hábitos de la identidad. Relaciones 21 (83): 39-66.

TEXIDÓ, E. y J. GURRIERI. 2012. Panorama migratorio de América del Sur 2012, Organización Internacional para las Migraciones (OIM), Buenos Aires. 
VERTOVEC, S. 2003. Migration and Other Modes of Transnationalism: Towards Conceptual Cross-Fertilization. International Migration Review 37: 641-665.

VILA, P. 2001. Versión estadounidense de la teoría de frontera: una crítica desde la etnografía. Papeles de Población 30: 11-30.

WALDINGER, R. 2013. Immigrant transnationalism. Current Sociology 61: 756-777.

ZAPATA-BARRERO, R. y X. FERRER-GALLARDO. 2012a. Fronteras en movimiento. Migraciones hacia la Unión Europea en el contexto Mediterráneo. Edicions Bellaterra, Barcelona.

2012b. Las fronteras en la época de la movilidad. En Fronteras en movimiento. Migraciones hacia la Unión Europea en el contexto Mediterráneo, R. Zapata-Barrero y X. Ferrer-Gallardo (Eds.), pp. 11-56. Edicions Bellaterra, Barcelona.
ZOFRI. 2006. Memoria Anual Zona Franca de Iquique S.A. Plataforma de negocios del Cono Sur. ZOFRI S.A., Iquique.

ZÚÑIGA, V. 2009. Tratando de entender la sociedad fronteriza: recorrido crítico de los estudios mexicanos sobre la cultura en la frontera México - Estados Unidos (1976-2000). En Migraciones contemporáneas. Contribución al debate, H. Mazurek (Ed.), pp. 6984. Postgrado en Ciencias del Desarrollo CIDES-UMSA, La Paz.

2011. La diversidad de las sociedades fronterizas México/ Estados Unidos. Frontera Norte 23 (45): 287-295.

\section{Periódicos}

EL PERIODISTA. (4 de septiembre 2014). Cifras de envejecimiento y migración muestran un Chile distinto al de hace un decenio, En: http://elperiodistaonline.cl/salud/2014/og/cifrasde-envejecimiento-y-migracion-muestra-un-chile-distinto-al-dehace-un-decenio/ Consultado el 5 de marzo de 2015 